\title{
Preparation \& Characterization of Al-5083 Alloy Composites
}

\author{
Sourabh Gargatte ${ }^{*}$, Rahul R. Upadhye, Venkatesh S. Dandagi, \\ Srikanth R. Desai, Bhimappa S. Waghamode \\ Department of Industrial \& Production Engineering, B. V. B. College of Engineering \& Technology, Hubli, India \\ Email: ${ }^{*}$ sourabhgargatte@gmail.com, srikanthdesai4@gmail.com, vdandagi06@gmail.com
}

Received September 17, 2012; revised October 25, 2012; accepted November 5, 2012

\begin{abstract}
This paper reports the dry sliding wear behavior \& Brinell hardness test of AA 5083 aluminium reinforced with SiC particles fabricated by stir casting technique. Different volume fraction of $\mathrm{SiC}$ particles $(3,5$ and $7 \mathrm{wt} \%$ ) were used for synthesis. The wear test has been conducted on pin-on-disc testing machine to examine the wear behaviour of the aluminium alloy and its composites. An attempt has been made to study the influence of wear parameters like applied load, sliding speed, sliding distance and percentage of reinforcement on the dry sliding wear of metal matrix composites (MMCs). A plan of experiments, based on the techniques of Taguchi, was performed to acquire data in controlled way. An orthogonal array of $\mathrm{L}_{9}\left(3^{4}\right)$ and signal to noise ratios as smaller the better was selected. Analysis of variance (ANOVA) was employed to investigate the influence of wear parameter on pin of aluminium MMCs. The correlation was obtained by multiple general regressions model. Finally, conformation tests were done to make a comparison between the experimental results foreseen from the mentioned correlation.
\end{abstract}

Keywords: Metal Matrix Composites; Wear; Brinell Hardness; Orthogonal Array; Analysis of Variance; Taguchi Method

\section{Introduction}

Conventional monolithic materials have limitations with respect to achievable combinations of strength, stiffness, and density. In order to overcome these shortcomings and to meet the ever-increasing engineering demands of modern technology, Metal Matrix Composites (MMCs) are gaining importance. In recent years, discontinuously reinforced aluminium (DRAMMCs) based metal matrix composites have attracted worldwide attention as a result of their potential to replace their monolithic counterparts primarily in automobile and energy sector.

Aluminium Matrix Composites (AMCs) refer to the class of light weight high performance aluminium centric material systems. The reinforcement in AMCs could be in the form of continuous/discontinuous fibers, whisker or particulates, in volume fractions ranging from a few percent to $50 \%$. Aluminium matrix composites are designed to have the toughness of the alloy matrix and the hardness, stiffness and strength of hard ceramic reinforcements. So, the major advantages of AMCs compared to unreinforced materials are as follows: greater strength, improved stiffness, reduced density, good corrosion resistance, improved high temperature properties, controlled thermal expansion coefficient, thermal/heat

\footnotetext{
${ }^{*}$ Corresponding author.
}

management, enhanced and tailored electrical performance, improved wear resistance and improved damping capabilities. The most commonly employed Metal Matrix Composites (MMCs) consists of aluminium alloy reinforced with hard ceramic particles usually silicon carbide, alumina and soft particles usually graphite, talc. Silicon carbide ( $\mathrm{SiC}$ ) are known for low density, high strength, low thermal expansion, high thermal conductivity, high hardness, high elastic modulus, excellent thermal shock resistance and superior chemical inertness [1,2].

Metal Matrix Composites (MMCs) are conventionally fabricated using different techniques such as powder metallurgy, squeeze casting, semi-solid stirring process. Stir casting is considered to be best method to prepare large quantity of composites due to its processing simplicity, flexibility \& low cost. An inherent difficulty in fabrication of $\mathrm{SiC}-\mathrm{Al}$ alloy composites is that molten $\mathrm{Al}$ alloys normally do not wet considerably the ceramic reinforcements. Good interfacial bond strength between SiC-Al alloy composites can be achieved by optimizing stirring parameters, such as stir temperature and speed. It is well known that the $\mathrm{SiC}$ reinforcement tend to react with Aluminium during processing, leading to the formation of $\mathrm{Al}_{4} \mathrm{C}_{3}$ and $\mathrm{Si}$ at the interface. Efforts have been directed to prevent the chemical reaction at interfaces by 
oxidation of $\mathrm{SiC}$, coating of $\mathrm{SiC}$ particles, or alloying of $\mathrm{Al}$ matrix with $\mathrm{Mg}$ or $\mathrm{Si}$.

Magnesium addition to aluminum reduces its casting fluidity at the same time as it reduces the surface tension of the aluminum sharply. The presence of magnesium in aluminum alloy matrix during composite fabrication not only strengthens the matrix but also scavenges the oxygen from the surface of the dis-persoid, leading to an increase in the surface energy, of the dis-persoids. It can reduce $\mathrm{Al}_{2} \mathrm{O}_{3}$, either to form $\mathrm{Al}, \mathrm{MgAl}_{2} \mathrm{O}_{4}$ or $\mathrm{MgO}$ depending upon its concentration [3-7].

Applications of AMCs materials take place in automobile, mining, mineral, aerospace, defense and other related sectors. In the automobile sector, Al composites are used for making various components such as brake drum, cylinder liners, cylinder blocks, disk brakes, piston crown and drive shaft [8]. In general, these materials are developed for the production of high wear resistant components. The major part of application of AMCs includes moving and sliding parts, hence the study of wear properties of these materials is very important to enhance the understanding of the behavior of these materials while in service application.

Wear is a surface phenomenon that occurs by displacement and detachment of material because wear usually implies a progressive loss of weight and alteration of dimensions over a period of time. All mechanical components that undergo sliding or rolling contact are subject to some degree of wear. Such components are bearings, gears, seals, guides, piston rings, piston crown, disk brakes and clutches.

Hardness is defined as the ability of a material to resist plastic deformation. It is the property of a metal, which gives it the ability to resist being permanently, deformed (bent, broken or have its shape changed), when a load is applied. The greater the hardness of the metal, the greater resistance it has to deformation.

On the present investigation an attempt is made to find the influence of wear parameters on dry sliding wear of the composites and to establish correlation between sliding speed, load, sliding distance, percentage of reinforcement and combined effect of these parameters on dry sliding wear of the composites and to carry out Brinell hardness test on composite specimens.

\section{Literature Review}

A number of research works have been proposed to explain the sliding wear behavior of composites.

Dry sliding wear characteristics of Al-SiCp based composites by Taguchi Approach was undertaken by S. Basavarajappa and G. Chandramohan [9], fabricated successfully by liquid metallurgy stir casting technique. Experiment was carried out using a pin-on-disc machine. In their studies, addition of $\mathrm{SiC}$ reinforcement has been found to reduce the wear rate, compared to matrix alloy. Results of ANOVA, indicates sliding distance \& load has major influence for mass loss. During the rubbing action between the surfaces, the exposed particles of $\mathrm{SiC}$, causes the scratching of counter surface, subsequently resulting in oxidation of surface. The formation of thin film of oxide layer acts as contaminant layers between the sliding surfaces, resulting reduce wear. At higher load and increased sliding distance, the oxide layer is removed resulting in increased mass loss.

The wear properties of the Al-Mg-Cu alloys were considerably improved by the addition of $\mathrm{SiC}$ particles; however, wear resistance of the composites was much higher than that of the unreinforced aluminium alloys. Addition of $\mathrm{SiC}$ particles caused improvement of wear resistance of Al-4 wt $\% \mathrm{Mg}-\mathrm{Cu}$ alloy. The hardness and wear resistance of $\mathrm{Al}-4 \mathrm{wt} \% \mathrm{Mg}$ alloy increased with increase of copper contains up to $5 \mathrm{wt} \%$, successfully fabricated by liquid metallurgy method by Adel Md Hassan [10].

It is observed from the literature review that the wear behavior of composite is influenced by operating parameters like sliding speed, load, sliding distance \& percentage reinforcement. And by adopting Taguchi's optimization method, the results were nearly accurate to the predicted values. The wear resistance and overall mechanical properties has improved by increase of percentage reinforcement of particulates in the matrix.

\section{Taguchi Technique}

The Taguchi method drastically reduces the number of experiments that are required to model the response function compared with the full factorial design of experiments. The major advantage of this technique is to find out the possible interaction between the parameters. The Taguchi technique is devised for process optimization and identification of optimal combination of the factors for a given response [11]. This technique is divided into three main phases, which encompasses all experimentation approaches. The three phases are 1) The planning phase; 2) The conducting phase and 3) The analysis phase. Planning phase is the most important phase of the experiment. This technique creates a standard orthogonal array to accommodate the effect of several factors on the target value and defines the plan of experiments. The experimental results are analyzed using analysis of means and variance to study the influence of factors.

\section{Experimental}

\subsection{Materials}

The DRAMMC material selected for the present investigation was based on Al-Mg matrix alloy, designated as aluminium association as AA 5083. This matrix alloy has low density $2.6 \mathrm{gm} / \mathrm{cm}^{3}$ among all $\mathrm{Al}$ alloys and provides 
excellent combination of strength, high corrosion resistance to seawater, high tensile strength, exceptionally tough and good machinability \& weldability. The Table 1 shows chemical composition of AA 5083 found out by Spectro analysis. The $\mathrm{SiC}$ particles, which were used to fabricate the composite, the particle size range from 1 25 microns.

\subsection{Preparation of the Composite}

The synthesis of particulate metal matrix composites (MMCs) used in the present study was carried out by the liquid metallurgy Stir casting method to prepare composite specimens. This method is most economical to fabricate composites particulates. In this process, matrix alloy (AA5083) was firstly superheated over its melting temperature up to $760^{\circ} \mathrm{C}$ in electric furnace. The slurry was degassed and slag powder was sprayed to remove any slag content. The temperature was lowered gradually below the liquidus temperature at $720^{\circ} \mathrm{C}$. At this temperature, the $\mathrm{SiC}$ particles, preheated at $800^{\circ} \mathrm{C}$ to form a layer of $\mathrm{SiO}_{2}$ on their surface to improve their wettability with molten metal, were incorporated into the slurry by weight ratio. The slurry temperature was increased and automatic stirring was continued for $10 \mathrm{~min}$ at an average stirring speed of $450 \sim 500 \mathrm{rpm}$. The melt was superheated above liquidus temperature and finally poured into the Cast Iron (CI) permanent moulds of $20 \mathrm{~mm}$ in diameter and height of $210 \mathrm{~mm}$. SiC reinforcement percentage were 3, 5 and $7 \mathrm{wt} \%$. Figure 1 shows the melting and stirring mechanism and CI permanent moulds.

\subsection{Experimental Setup and Procedure}

\subsubsection{Wear}

A pin on disc model (model type, TR-201CL of Ducom,

Table 1. Composition of AA 5083 wt \%.

\begin{tabular}{lc}
\hline $\mathrm{Al}$ & Balance \\
\hline $\mathrm{Si}$ & 0.0960 \\
$\mathrm{Fe}$ & 0.161 \\
$\mathrm{Cu}$ & 0.0270 \\
$\mathrm{Mn}$ & 0.600 \\
$\mathrm{Mg}$ & 3.92 \\
$\mathrm{Cr}$ & 0.0790 \\
$\mathrm{Ni}$ & 0.0008 \\
$\mathrm{Zn}$ & 0.0270 \\
$\mathrm{Ti}$ & 0.0660 \\
$\mathrm{Sb}$ & 0.002 \\
$\mathrm{Sn}$ & 0.001 \\
\hline
\end{tabular}

India), was used to investigate the dry sliding wear char acteristics of composite as per ASTM G99 - 95 standards. The wear specimen (pin) of $8 \mathrm{~mm}$ diameter and $25 \mathrm{~mm}$ height was cut from as cast samples machined. The weight of specimen was measured on a digital micro balance weighing machine with an accurate $0.1 \mathrm{mg}$ and initial weight of the specimen was noted. During the test the pin was pressed against the counterpart, rotating against EN32 steel disc with hardness of $65 \mathrm{HRC}$, shown in Figure 2. After running through a fixed sliding distance, the specimen were removed and weighed to determine the weight loss due to wear. The difference in the weight measured before and after test gave the sliding wear of the composite specimen and then volume loss is calculated.

\subsubsection{Hardness}

Brinell hardness test was used to investigate the hardness of composite specimens as per ASTM E-10 standard. The specimens of $20 \mathrm{~mm} \times 20 \mathrm{~mm}$ were cut from as cast condition and specimen surfaces were polished. Brinell hardness test is conducted for soft material like aluminum, aluminum alloy with a load of $500 \mathrm{kgf}$. The hardened-steel round ball of $10 \mathrm{~mm}$ diameter was used as penetrator, Brinell hardness samples shown in Figure 3.
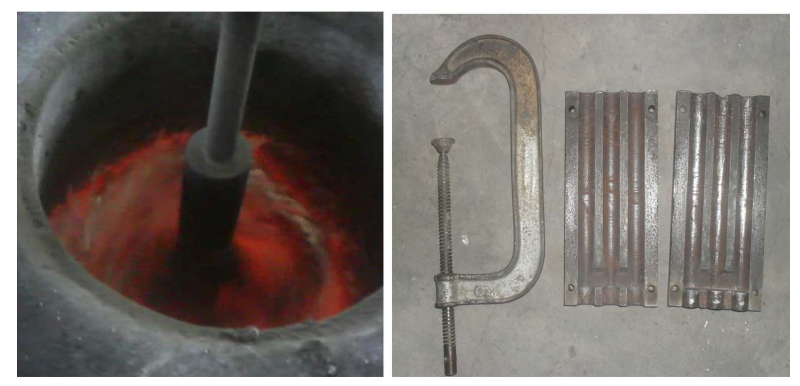

Figure 1. Preparation of Al-5083 composite \& CI permanent mould.

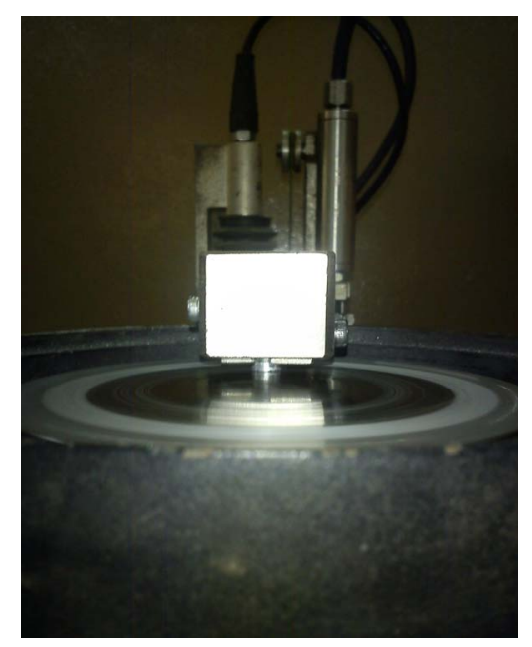

Figure 2. Pin on disc setup. 


\subsection{Plan of Experiment}

\subsubsection{Wear Test}

The experiments were conducted as per the standard Taguchi's orthogonal array. The selection of the orthogonal array was based on the condition that the degrees of freedom for the orthogonal array should be greater than or equal to sum of those wear parameters. In the present investigation an $\mathrm{L}_{9}\left(3^{4}\right)$ orthogonal array was chosen, which has 9 rows and 4 columns as shown in Table 2 . In the present investigation the wear parameters chosen for the experiments were 1) sliding speed, 2) load, 3) sliding distance, 4) weight percentage of $\mathrm{SiC}$. Table 3 indicates the factors and their level. The experiment consists of 9 tests (each row in the $\mathrm{L}_{9}$ orthogonal array) and the columns were assigned with parameters.

The first column in Table $\mathbf{3}$ was assigned to sliding speed, second column was assigned to load, third column was assigned to sliding distance and the fourth column was assigned to weight percentage of $\mathrm{SiC}$. The response to be studied was the wear with the objective as smaller the better $\mathrm{S} / \mathrm{N}$ ratio.

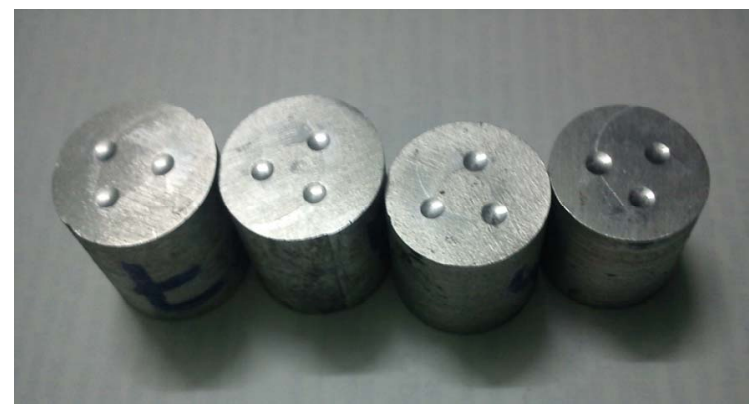

Figure 3. Hardness specimens of Al-5083 composites.

Table 2. Orthogonal array $L_{9}\left(3^{4}\right)$ of Taguchi.

\begin{tabular}{ccccc}
\hline $\mathrm{L}_{9}\left(3^{4}\right)$ test & 1 & 2 & 3 & 4 \\
\hline 1 & 1 & 1 & 1 & 1 \\
2 & 1 & 2 & 2 & 2 \\
3 & 1 & 3 & 3 & 3 \\
4 & 2 & 1 & 2 & 3 \\
5 & 2 & 2 & 3 & 1 \\
6 & 2 & 3 & 1 & 2 \\
7 & 3 & 1 & 3 & 2 \\
8 & 3 & 2 & 1 & 3 \\
9 & 3 & 3 & 2 & 1 \\
\hline
\end{tabular}

Table 3. Process parameters with their values at three levels.

\begin{tabular}{ccccc}
\hline Level & $\begin{array}{c}\text { Sliding speed } \\
\mathrm{m} / \mathrm{s}\end{array}$ & $\begin{array}{c}\text { Load } \\
\mathrm{N}\end{array}$ & $\begin{array}{c}\text { Sliding distance } \\
\mathrm{m}\end{array}$ & $\begin{array}{c}\mathrm{SiC} / \mathrm{wt} \\
\mathrm{pct}\end{array}$ \\
\hline 1 & 0.314 & 9.81 & 500 & 3 \\
2 & 0.942 & 29.43 & 1000 & 5 \\
3 & 1.570 & 49.05 & 1500 & 7 \\
\hline
\end{tabular}

\section{Results and Discussion}

\subsection{Hardness}

Brinell hardness test was carried out on Al-5083 SiC composites and average of three reading for each specimen was calculated. Table 4 \& Figure 4 show the variation of Brinell hardness number respect to different percentage of reinforcement. Al-5083 reinforced with 3, 5, \& 7 wt pet of $\mathrm{SiC}$ shows greater Brinell hardness number compared base metal. As the reinforced percentage of $\mathrm{SiC}$ has increased the Brinell hardness number has increased.

\subsection{Wear Test}

The plan of tests was developed with the aim of relating the influence of sliding speed, load, sliding distance \& reinforcement percentage with dry sliding wear of the composite. On conducting experiments as per orthogonal array $\mathrm{L}_{9}\left(3^{4}\right)$, the wear results for various combinations of parameters were obtained and are shown in Table 5.

\subsection{Main Effects}

The values of wear rate for each factor i.e. sliding speed, load, sliding distance $\&$ reinforcement percentage at each level i.e. level 1, level 2 and level 3 was obtained and results is summarized in Tables 5 and $\mathbf{6}$ presents the main effect graph for wear rate. The quality characteristics investigated in this study was "smaller the better".

\subsection{Signal to Noise Ratios (S/N)}

The signal to noise ratio measures the sensitivity of the

Table 4. Brinell hardness test.

\begin{tabular}{ccccc}
\hline & 0 & 3 & 5 & 7 \\
\hline \multirow{3}{*}{ BHN readings } & 53.7 & 60.5 & 63.3 & 59.7 \\
& 59.0 & 60.1 & 62.9 & 64.6 \\
Mean BHN value & 59.7 & 57.9 & 64.6 & 65.9 \\
\hline
\end{tabular}

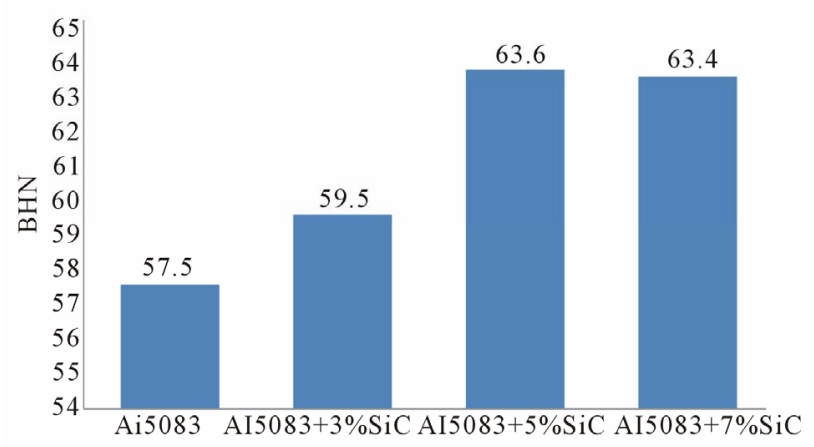

Figure 4. Brinell hardness number of Al-5083 composite. 
Table 5. Orthogonal array of Taguchi for wear $L_{9}$ array.

\begin{tabular}{ccccccc}
\hline Test & $\begin{array}{c}\text { Sliding } \\
\text { speed } \\
\mathrm{m} / \mathrm{s}\end{array}$ & $\begin{array}{c}\text { Load } \\
\mathrm{N}\end{array}$ & $\begin{array}{c}\text { Sliding } \\
\text { distance } \\
\mathrm{m}\end{array}$ & $\begin{array}{c}\text { SiC/wt } \\
\mathrm{pct}\end{array}$ & $\begin{array}{c}\text { Wear } \\
\text { rate } 10^{-11} \\
\mathrm{~m}^{2} / \mathrm{N}\end{array}$ & $\mathrm{S} / \mathrm{N}$ ratio \\
\hline 1 & 0.314 & 9.81 & 500 & 3 & 9.330 & -19.39 \\
2 & 0.314 & 29.43 & 1000 & 5 & 6.370 & -16.08 \\
3 & 0.314 & 49.05 & 1500 & 7 & 4.598 & -13.25 \\
4 & 0.942 & 9.81 & 1000 & 7 & 0.111 & 19.09 \\
5 & 0.942 & 29.43 & 1500 & 3 & 2.160 & -6.68 \\
6 & 0.942 & 49.05 & 500 & 5 & 0.100 & 20 \\
7 & 1.570 & 9.81 & 1500 & 5 & 0.050 & 26.02 \\
8 & 1.570 & 29.43 & 500 & 7 & 0.453 & 6.87 \\
9 & 1.570 & 49.05 & 1000 & 3 & 0.141 & 17.01 \\
\hline
\end{tabular}

Table 6. Response table for $\mathrm{S} / \mathrm{N}$ ratio smaller the better

\begin{tabular}{ccccc}
\hline Level & $\begin{array}{c}\text { Sliding Speed } \\
\text { (A) }\end{array}$ & $\begin{array}{c}\text { Load } \\
\text { (B) }\end{array}$ & $\begin{array}{c}\text { Sliding } \\
\text { Distance } \\
\text { (C) }\end{array}$ & $\begin{array}{c}\text { SiC wt pct } \\
\text { (D) }\end{array}$ \\
\hline 1 & -16.244 & 8.572 & 2.493 & -3.024 \\
2 & 10.801 & -5.298 & 6.675 & 9.979 \\
3 & 16.638 & 7.921 & 2.027 & 4.240 \\
\hline
\end{tabular}

quality investigated to those uncontrollable factors in the experiment. The higher value of $\mathrm{S} / \mathrm{N}$ ratio is always desirable because greater $\mathrm{S} / \mathrm{N}$ ratio will result in smaller product variance around the target value. As mentioned earlier the quality characteristic used in this study was "Smaller the better". The S/N ratio analysis was performed using statistical software "MINITAB R15".

From Table 5 it can be seen that wear rate of experiment number 7 is smaller and $\mathrm{S} / \mathrm{N}$ ratio is largest. Based on main effects of $\mathrm{S} / \mathrm{N}$ ratio, from the Figure 5 the optimal combination of parameters and their levels for achieving minimum wear rate is $\mathrm{A}_{3} \mathrm{~B}_{1} \mathrm{C}_{2} \mathrm{D}_{2}$ i.e. sliding speed at level $3(1.57 \mathrm{~m} / \mathrm{s})$, load at level $1(9.81 \mathrm{~N})$, sliding distance at level $2(1000 \mathrm{~m}) \& \mathrm{wt} \%$ of $\mathrm{SiC}$ at level 2 (5 wt\%).

\subsubsection{Effect of Sliding Speed}

The influence of sliding speed on wear rate is depicted in Table 5. From the table it can be inferred the wear mechanism strongly dependent on the sliding speed. Atlow sliding speed the wear rate of composite is higher and the sliding speed as increases from 0.314 to 1.570 $\mathrm{m} / \mathrm{s}$ the wear rate was observed to decrease. This is because during the rubbing action between the surfaces, the exposed particles of $\mathrm{SiC}$, causes the scratching of counter surface, subsequently resulting in oxidation of surface. The formation of thin film of oxide layer acts as contaminant layers between the sliding surfaces, resulting

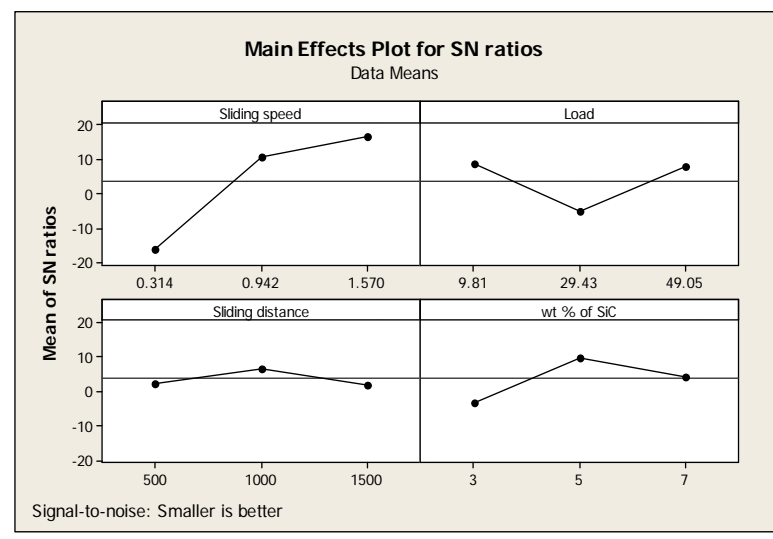

Figure 5. Main effects plot for $\mathrm{S} / \mathrm{N}$ ratios.

reduce wear. At higher load and increased sliding distance, the oxide layer is removed resulting in increased mass loss.

\subsubsection{Effect of Applied Load}

Increase in the addition of $\mathrm{SiC}$ restricts the flow or deformation of matrix material with respect to load. At lower load the wear rate for $3 \mathrm{wt} \%$ is greater but for same load for $7 \mathrm{wt} \%$ is less and for $5 \mathrm{wt} \%$ wear rate is lesser compared to $3 \& 7 \mathrm{wt} \%$. For higher load $(49.05 \mathrm{~N})$, wear rate has observed higher for $7 \%$ reinforcement with respect to sliding distance.

\subsubsection{Effect of Reinforcement Percentage}

High wear resistance of composites materials is due to the presence of $\mathrm{SiC}$ particles that act as load-supporting elements. The effect of wear rate for different values of speed, load \& distance is shown in Table 5. As the reinforcement percentage from $3 \%$ to $7 \mathrm{wt} \%$ increases, it is observed that the wear rate has decreased with respect to speed, load \& distance. The addition of SiC particles increases the hardness which may increases the wear resistance of the composites.

\subsection{Analysis of Variance (ANOVA)}

Analysis of variance was performed using statistical software "MINITAB R15". ANOVA has been carried out to analyze the influence of wear parameter 1) Sliding speed, 2) Load, 3) Sliding distance and 4) Weight percentage of $\mathrm{SiC}$ particles. The analysis was carried out for a level of significance of $5 \%$ (i.e. the level of confidence 95\%). Table 7 shows the results of ANOVA analysis. One can observe from ANOVA analysis that 1) sliding speed, 2) Load, 3) sliding distance and 4) weight percentage of $\mathrm{SiC}$ particles has the influence on wear of the composite. The last column in Table 7 shows percentage contribution (p) of factors on the total variation indicating their degree of influence the results.

One can observe from ANOVA table the sliding speed 
$(\mathrm{p}=84.46 \%)$ has major influence on wear rate, load $(\mathrm{p}=4.65 \%)$ and weight percentage of $\mathrm{SiC}(\mathrm{p}=8.31 \%)$ has moderate influence on wear rate and sliding distance $(p=2.39 \%$ ) has negligible influence on wear rate. The sliding distance is influencing comparatively less $(\mathrm{p}=$ $2.39 \%$ ) which indicates that there is no appreciable increase in wear by increasing the sliding distance from 500 to $1500 \mathrm{~m}$.

The ANOVA has resulted in zero degree of freedom for error term, it is necessary to pool the factor having less influence, for correct interpretation of results. In Table 8 shows F-test, if $\mathrm{F}>4$, then it means that the change of the design parameter has significant effect on quality characteristic. Table 8 shows pooled ANOVA table, shows that the pooled error is $2 \%$ were important factors are not omitted from experiments

\subsection{General Regression Analysis}

To establish correlation between the wear parameters 1) Sliding speed, 2) Load, 3) Sliding distance, 4) Weight percentage of $\mathrm{SiC}$ particles and dry sliding wear, General regression model was obtained using statistical software "MINITAB R15". The terms that are statistically significant are included in model. The regression co-efficient of model is 0.82 The equation obtained as follows $\mathrm{W}=12.4-5.22$ Sliding speed -0.0395 Load -0.00102 Sliding distance $-0.539 \mathrm{SiC} / \mathrm{wt}$ pct-(1)

The sliding wear of composites can be calculated by substituting the recorded values of variables for the

Table 7. Summary of ANOVA.

\begin{tabular}{ccccc}
\hline & $\begin{array}{c}\text { Degree of } \\
\text { freedom }\end{array}$ & $\begin{array}{c}\text { Sum of } \\
\text { squares }\end{array}$ & $\begin{array}{c}\text { Mean } \\
\text { square }\end{array}$ & $\begin{array}{c}\text { Percentage } \\
\text { contribution } \\
(\mathrm{p}) / \%\end{array}$ \\
\hline $\begin{array}{c}\text { Sliding speed } \\
\text { Load }\end{array}$ & 2 & 78.960 & 39.480 & 84.46 \\
$\begin{array}{c}\text { Sliding } \\
\text { distance }\end{array}$ & 2 & 4.341 & 2.171 & 4.65 \\
SiC/wt pct & 2 & 2.236 & 1.118 & 2.39 \\
Error & 0 & 7.757 & 3.879 & 8.31 \\
Total & 8 & - & - & \\
\hline
\end{tabular}

Table 8. Summary of pooled ANOVA.

\begin{tabular}{cccccc}
\hline Factors & $\begin{array}{c}\text { Degree } \\
\text { of } \\
\text { freedom }\end{array}$ & $\begin{array}{c}\text { Sum of } \\
\text { squares }\end{array}$ & $\begin{array}{c}\text { Mean } \\
\text { square }\end{array}$ & F-Test & $\begin{array}{c}\text { Percentage } \\
\text { contribution } \\
(\mathrm{p}) / \%\end{array}$ \\
\hline $\begin{array}{c}\text { Sliding } \\
\text { speed }\end{array}$ & 2 & 78.960 & 39.480 & 35.31 & 84.46 \\
Load & 2 & 4.341 & 2.171 & 1.94 & 4.65 \\
$\begin{array}{c}\text { SiC/wt } \\
\text { pct }\end{array}$ & 2 & 7.757 & 3.879 & 3.47 & 8.31 \\
$\begin{array}{c}\text { Error } \\
\text { Total }\end{array}$ & 2 & 2.236 & 1.118 & & \\
\hline
\end{tabular}

Equation (1). The positive value of co-efficient suggests that the sliding wear of material increases with their associated variables. Whereas the negative value of the coefficient suggests that the sliding wear of the material will decreases with the increase in associated variables. The magnitude of the variables indicates the weightage of each of these factors. It is observed from Equation (1) that the sliding speed has major effect on wear of the composites, which is followed by reinforcement, applied load and sliding distance for the tested range of the variables.

\subsection{Confirmation Test}

Once the optimal combination of process parameters and their levels was obtained, the final step was to verify the estimated results against experimental value. It may be noted that if the optimal combination of parameters and their levels coincidently match with one of the experiments in the orthogonal array (OA), then no confirmation test is required.

Confirmation test was required in present case because the optimum combination of parameter and their levels i.e. $\mathrm{A}_{3} \mathrm{~B}_{1} \mathrm{C}_{2} \mathrm{D}_{2}$ did not correspond to any experiment of the orthogonal array.

One tray at optimal combination of parameter and their levels $A_{3} B_{1} C_{2} D_{2}$ experiment was conducted on pinon-disc machine. The value of wear rate obtained from experiment was compared with estimated value from the regression model Equation (1) as shown in Table 9. It can be seen from this Table 9 the difference between experimental results and the estimated results is 0.009 . This indicates that the experimental result of wear rate is close to the estimated value. This verifies that the experimental results are strongly correlated with the estimated result, as the error is $8.1 \%$.

\section{Conclusions}

From the analysis on the results of dry sliding wear of the $\mathrm{SiC}$ particles reinforced MMCs and results of hardness of material obtained, the following conclusions can be drawn from the study.

1) A Taguchi orthogonal array, the signal to noise (S/N) ratio, analysis of variance (ANOVA) and General regression model were successfully used for optimization of wear parameters.

Table 9. Results of confirmation experiment.

\begin{tabular}{ccccc}
\hline \multicolumn{5}{c}{ Optimal Condition } \\
\hline Experiment & $\begin{array}{c}\text { Regression model } \\
\text { Equation (1) }\end{array}$ & Difference & $\begin{array}{c}\text { Error } \\
(\%)\end{array}$ \\
\hline Level & $\mathrm{A}_{3} \mathrm{~B}_{1} \mathrm{C}_{2} \mathrm{D}_{2}$ & $\mathrm{~A}_{3} \mathrm{~B}_{1} \mathrm{C}_{2} \mathrm{D}_{2}$ & - & \\
$\begin{array}{c}\mathrm{Wear} \text { rate } \\
\mathrm{m}^{2} / \mathrm{N}\end{array}$ & 0.111 & 0.102 & 0.009 & 8.1 \\
\hline
\end{tabular}


2) Based on main effects of $\mathrm{S} / \mathrm{N}$ ratios the optimal combination of parameters and their levels for achieving minimum wear rate is $\mathrm{A}_{3} \mathrm{~B}_{1} \mathrm{C}_{2} \mathrm{D}_{2}$ i.e. sliding speed at level $3(1.57 \mathrm{~m} / \mathrm{s})$, load at level $1(9.81 \mathrm{~N})$, sliding distance at level $2(1000 \mathrm{~m}) \&$ wt pct of $\mathrm{SiC}$ at level $2(5$ $w t \%)$.

3) From the ANOVA analysis, results shows that sliding speed $(\mathrm{p}=84.46 \%)$ has major influence on wear rate, load $(\mathrm{p}=4.65 \%)$ and weight percentage of $\mathrm{SiC}(\mathrm{p}=$ $8.31 \%$ ) has moderate influence on wear rate and sliding distance $(p=2.39 \%)$ has negligible influence on wear rate. The Pooled error is $2 \%$ for the factors and co-efficient of regression value of 0.82 shows satisfactory correlation was obtained.

4) A General regression mathematical model has been successfully developed to predict the wear rate of AA5083-SiC particle composite. The developed model can be effectively used to predict the wear rate of composite at $95 \%$ confidence level within the range of investigation.

5) The confirmation test showed that error associated with dry sliding wear of composite with combination of optimal parameter $\mathrm{A}_{3} \mathrm{~B}_{1} \mathrm{C}_{2} \mathrm{D}_{2}$ is $8.1 \%$.

6) It was observed that the wear rate decreased for increasing the reinforcement percentage of $\mathrm{SiC}$ particles. Al-5083 reinforced with $3,5 \& 7$ wt pct shows lesser wear rate compared with pure Al-5083 alloy.

The hardness of Al-5083 increased considerably with increase in $\mathrm{SiC}$ particles up to $7 \mathrm{wt} \%$.

\section{Acknowledgements}

The authors like to thank Prof. N. Vijaya Kumar, Dr. V. N. Gaitonde, Prof B. S. Kakol, Dr. B. B. Kotturshettar, Prof S. B. Burli, Prof Vijay Jatti, Prof Siddhalingeshwar, Om Gargatte and our parents. Authors also thank Department of Industrial \& Production Engineering, B. V. B College of Engineering \& Technology Hubli, Universal Trading Corporation Mumbai, Ghousia College of Engineering Bangalore, Basaveshwar Engineering College, Bagalkot, Karnataka Material Testing \& Research Centre and More Metals, Mumbai.

\section{REFERENCES}

[1] K. Chawla, "Composite Material Science and Engineering," 2nd Edition, Springer, New Delhi, 2006.

[2] B. Cantor, F. Dunne and I. Stone, "Metal and Ceramic Matrix Composites," Institute of Physics Publishing, London, 2004.

[3] Z. L. Shi, S. Ochiai, M. Hojo, J. Lee, M. Y. Gu, H. Lee and R. J. Wu, "The Oxidation of SiC Particles and Its Interfacial Characteristics in Al-Matrix Composites" Journal of Materials Science, Vol. 36, No. 10, 2001, pp. 2441 2449.

[4] Z. L. Shi, M. Y. Gu, J. Y. Liu, G. Q. Liu, J.-C. Lee, D. Zhang and R. J. Wu, "Interfacial Reaction between the Oxidized SiC Particles and Al-Mg Alloy," Chinese Science Bulletin, Vol. 46, No. 3, 2001, pp. 1948-1952.

[5] R. Gurler, "Sliding Wear Behavior of a Silicon Carbide Particle-Reinforced Aluminum-magnesium Alloy," Journal of Material Science Letters, Vol. 18, No. 7, 1999, pp. 553-554. doi:10.1023/A:1006630612974

[6] S. Valdez, B. Campillo, R. Perez, L. Martinez and A. Garcia H. "Synthesis and Microstructural Characterization of Al-Mg Alloy-SiC Particle Composite," Material Letter, Vol. 62, No. 17-18, 2008, pp. 2623-2625. doi:10.1016/i.matlet.2008.01.002

[7] G. Lin, H. W. Zhang, H. Z. Li, L. N. Guan and L. J. Huang, "Effects of Mg Content on Microstructure and Mechanical Properties of SiCp/Al-Mg Composites Fabricated by Semi-Solid Stirring Technique," Transactions of Nonferrous Metals Society of China, Vol. 20, No. 10, 2010, pp. 1851-1855.

[8] M. K. Surappa, "Aluminum Matrix Composites: Challenges and Opportunities," Sadhana, Vol. 28, No. 1-2, 2003, pp. 319-334.

[9] S. Basavarajappa and G. Chandramohan, "Wear Studies on Metal Matrix Composites: A Taguchi Approach," Journal of Material Science \& Technology, Vol. 21 No. 6, 2005, pp. 845-850.

[10] A. M. Hassan, A. Alrashdan, M. T. Hayajneh, and A. T. Mayyas, "Wear Behavior of Al-Mg-Cu-Based Composites Containing SiC Particles," Tribology International, Vol. 42, No. 8, 2009, pp. 1230-1238.

[11] M. S. Phadke, "Quality Engineering Using Robust Design,” P. T. R Prentice-Hall, Inc., New Jersey, 1989. 